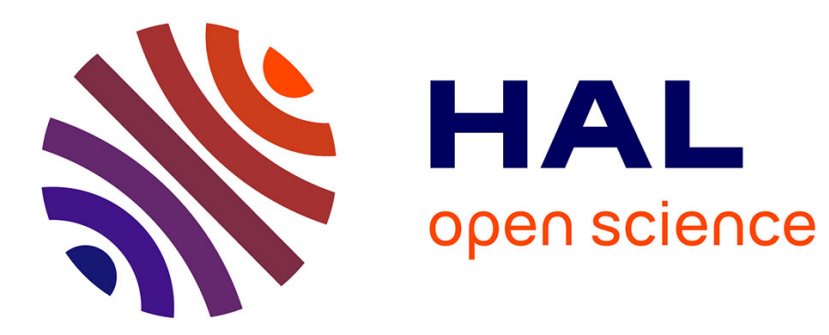

\title{
Molecular simulation of excimer fluorescence in polystyrene and poly(vinylcarbazole)
}

\author{
Pascal de Sainte Claire
}

\section{To cite this version:}

Pascal de Sainte Claire. Molecular simulation of excimer fluorescence in polystyrene and poly(vinylcarbazole). Journal of Physical Chemistry B, 2006, 110, pp.7334-7343. hal-00594588

\section{HAL Id: hal-00594588 \\ https://hal.science/hal-00594588}

Submitted on 20 May 2011

HAL is a multi-disciplinary open access archive for the deposit and dissemination of scientific research documents, whether they are published or not. The documents may come from teaching and research institutions in France or abroad, or from public or private research centers.
L'archive ouverte pluridisciplinaire HAL, est destinée au dépôt et à la diffusion de documents scientifiques de niveau recherche, publiés ou non, émanant des établissements d'enseignement et de recherche français ou étrangers, des laboratoires publics ou privés. 


\title{
Molecular Simulation of Excimer Fluorescence in Polystyrene and Poly(vinylcarbazole)
}

\author{
Pascal de Sainte Claire* \\ Laboratoire de Photochimie Moléculaire et Macromoléculaire, Ensemble Universitaire des Cézeaux, \\ UMR CNRS 6505, Université Blaise Pascal de Clermont-Ferrand, F-63177 Aubière Cedex, France
}

Received: December 1, 2005; In Final Form: February 8, 2006

\begin{abstract}
In fluorescence emission spectra of poly(vinylcarbazole) (PVK), two types of excimers are observed, the fully and the partially overlapped excimers, namely, excimers and exciplexes. In this work, we investigated the structural changes induced by the transition between electronic levels $S_{0}$ and $S_{1}$. Furthermore, the widely used assumption of similar potential energy surfaces in the $\mathrm{S}_{0}$ and $\mathrm{S}_{1}$ states and its use in molecular dynamics simulations are thoroughly examined for PVK and polystyrene (PS). The ground-state and excited-state intermolecular potentials between phenyl or carbazyl substituents in PS or PVK, respectively, are computed from high-level ab initio calculations and fit to analytic potentials. Finally, molecular dynamics simulations are performed at room temperature for PS and for isotactic and syndiotactic PVK. This treatment enabled the decoupling of excimer and exciplex contributions from the simulated spectra.
\end{abstract}

\section{Introduction}

The photophysical properties of aromatic-containing polymers have been extensively studied with fluorescence spectroscopy. ${ }^{1-10}$ Important structural information may be obtained from fluorescence spectra because both monomer and excimer emission are usually observed. Thus, the configuration of consecutive dyads in the polymer can be deduced from excimer intensity. In poly( $N$-vinylcarbazole) (PVK), ${ }^{4,11-13}$ two different configurations are responsible for excimer fluorescence. The totally eclipsed sandwich configuration (Figure 1a) gives rise to the low-energy emission band, whereas it is postulated that the partially overlapped excimer, the so-called exciplex (Figure 1b), is likely to be responsible for the high-energy band. ${ }^{3,14-16}$ Theoretical investigations based on molecular dynamics simulations of aromatic-containing polymers provide interesting results about the local macromolecular structure. ${ }^{15,17-22}$ These include the ratio of excimer to monomer emission and the nature and contribution of exciplexes to the overall fluorescence. However, these studies were performed on ground-state potential energy surfaces (PESs). It was postulated that groundstate and excited-state surfaces bore minor differences in the region of interest. The important interactions are (1) torsions about the polymer backbone, (2) intermolecular interactions, and (3) intramolecular van der Waals energy between consecutive chromophores. In our work, the above hypothesis is thoroughly investigated for polystyrene and poly $(N$-vinylcarbazole). First, high-level ab initio calculations of the ground state and the first excited state of the benzene dimer are presented. Next, the first electronic levels of the carbazole dimer are obtained from a combination of ab initio calculations and experimental fluorescence data. Then, adiabatic electronic PESs are fit with analytic model potentials and used in molecular dynamics (MD) simulations. The conformation changes induced by the electronic transition are carefully analyzed in the last section.

* Author to whom correspondence should be addressed. E-mail: pascal.de_sainte-claire@univ-bpclermont.fr.

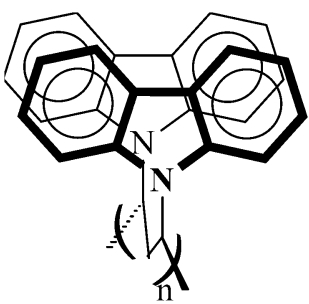

(a)

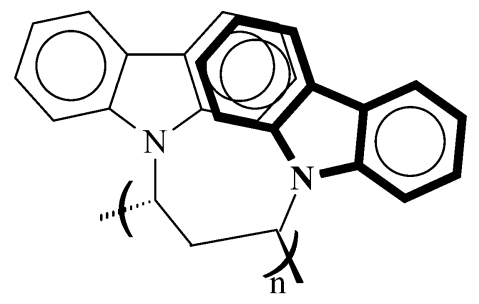

(b)
Figure 1. (a) Excimer and (b) exciplex configurations of the carbazole dimer in the poly $(N$-vinylcarbazole) polymer.

\section{Long-Range Potential of the Benzene Dimer and the Carbazole Dimer}

The configuration of consecutive chromophores in aromaticcontaining polymers is highly dependent on the magnitude of the long-range van der Waals potential energy. Excimer configurations are favored if this energy is strongly attractive. Thus, differences between the long-range potential in the ground state and the first excited state may play a significant role in the analysis of fluorescence spectra. In polystyrene and poly( $N$-vinylcarbazole), these interactions are those between phenyl and carbazyl substituents, respectively. This energy is computed below for configurations of the benzene dimer and the carbazole dimer that are representative of those in the macromolecule. The results are fit with Lennard-Jones analytic potentials, and a comparison is made with literature data. According to standard notations, ${ }^{23}$ the $\operatorname{tg}, \overline{\mathrm{g}} \overline{\mathrm{g}}$, and $\mathrm{gt}$ (respectively, tt, $\overline{\mathrm{g}} \overline{\mathrm{g}}$, and $\mathrm{gg}$ ) configurations of the racemic (respectively, meso) dyad give sandwich-like excimers. These conformations are obtained by selected rotations about one of the skeletal bonds that bears the substituent. Isotactic polymers are obtained from consecutive sequences of $\mathrm{tt}$ meso dyads, whereas syndiotactic polymers result from $\mathrm{tt}$ racemic dyads. These conformations are characterized by a set of dihedral angles that are represented in Figure 2a, namely, $\varphi_{1}$ and $\varphi_{2}$.

The first two electronic levels $S_{1}$ and $S_{2}$ in benzene are of $\mathrm{B}_{2 \mathrm{u}}$ and $\mathrm{B}_{1 \mathrm{u}}$ symmetry, respectively. The transitions from the ground state are symmetry-forbidden but are observed experi- 
(a)

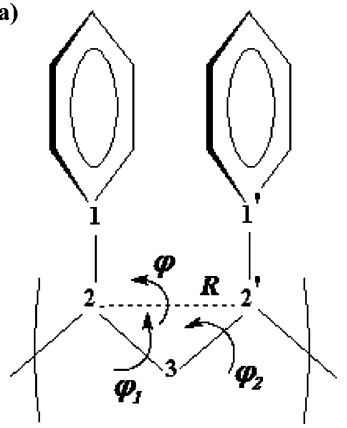

(b)

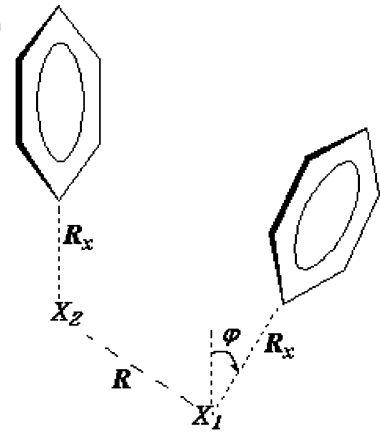

Figure 2. Definition of distances and dihedral angles used throughout. $R$ is the distance (a) between atoms 2 and $2^{\prime}$ in the macromolecule and (b) between ghost atoms $X_{1}$ and $X_{2} \cdot \varphi_{1}$ and $\varphi_{2}$ are dihedral angles defined by carbon atoms $1-2-3-2^{\prime}$ and $2-3-2^{\prime}-1^{\prime}$, respectively. $\varphi$ is the $1-2-2^{\prime}-1^{\prime}$ dihedral angle. $\varphi=0^{\circ}$ for the sandwich-like structure. The distance $R_{x}$ between one phenyl carbon atom and the dummy atom to which it is bonded is set to $1.5 \AA$. The phenyl rings are replaced by carbazyl substituents for PVK.

mentally, being vibronically induced. ${ }^{24}$ These states do not cross between the separated monomer and the excimer configurations. ${ }^{25}$ Moreover, rapid internal relaxation from $S_{2}$ to $S_{1}$ was reported for excimer and monomer configurations. Fluorescence experiments suggests that the $S_{2}$ lifetime of benzene is shorter than several picoseconds. ${ }^{26}$ In our work, we report MD simulations of the benzene dimer in the ground state and in the $S_{1}$ state. Thus, the $S_{1}$ state is most relevant to understand the local structure differences in the ground state and in the excited state prior to fluorescence.

For carbazole, the first two excited states $S_{1}$ and $S_{2}$ are closelying and dipole-allowed (short and long axis polarized, respectively ${ }^{27}$ ) although $S_{2}$ has the largest oscillator strength. In $N$-methyl carbazole, ZINDO/S calculations on RCIS/6-31G* geometries report 346.8 and $331.7 \mathrm{~nm}$ for $\mathrm{S}_{0} \rightarrow \mathrm{S}_{1}$ and $\mathrm{S}_{0} \rightarrow$ $\mathrm{S}_{2}$ transitions, respectively, i.e., less than $5 \mathrm{kcal} / \mathrm{mol}$ between these levels. ${ }^{28}$ Thus, internal relaxation is expected to occur much more rapidly than fluorescence. In addition, the $S_{1}$ and $\mathrm{S}_{2}$ states are expected to mix for intermediate fragment separation. This was observed for the dibenzofuran excimer. ${ }^{29}$ However, the excited-state potential in our work is derived from experimental fluorescence data (see the Carbazole Dimer/ Excited State section below for details) and thus represents the adiabatic potential surface of the state responsible for fluorescence. It should be noted that experimental fluorescence data were used appropriately in our work because an accurate highlevel ground-state PES was obtained.

Second, the carbazole species carries a dipole moment, and long-range dipole/dipole interactions may play a role in solutions of free carbazole molecules. However, in PVK, there is severe steric restriction because the carbazyl units are attached to the polymer backbone. The distance between neighboring carbazole units in the ground state is less than $4 \AA$ (see below). At this distance, the exchange energy interaction is predominant over the Coulombic Förster-type interaction. In addition, the fluorescence spectra of $r a c$ - and meso-2,4-di- $N$-carbazolylpentane, i.e., the dimer equivalent of PVK, are extremely similar to that of PVK. ${ }^{14}$ Thus, the essential features of the fluorescence in PVK can be represented by a dimer model. It should be noted, however, that long-range intramolecular electronic energy transfer between non-neighboring carbazyl units is likely to occur and may slow the fluorescence.

Last, excited-state properties have an incidence on absorption spectra. In our work, the excitation spectra are used to compare local structure configurations between the ground state and the

excited state prior to fluorescence. This is achieved by using the same states for excitation and emission. For this reason, our excitation spectra are not adequate representations of the actual experimental absorption spectra.

Computational Details. The benzene dimer has been the subject of experimental ${ }^{30-36}$ and theoretical interest for many years. ${ }^{24,37-45}$ In the ground state, two local minima have similar energies, the so-called T-shaped structure of $C_{2 v}$ symmetry and the parallel-displaced structure of $C_{2 h}$ symmetry. Although there is still controversy about the identity of the global minimum, it was shown that coupled-cluster calculations and appropriate correlation-consistent polarized valence double-zeta (cc-pvdz) basis sets described accurately the stability of these structures. ${ }^{42}$ In ref 42 , it was argued that standard cc-pvdz polarization Gaussian-type orbitals are to be replaced by more diffuse functions to obtain reliable correlation interaction energies. ${ }^{42,46}$

In this work, the ground-state energy of the benzene dimer is calculated with the second-order (MP2) and fourth-order (including single, double, and quadrupole excitations, i.e., MP4(SDQ)) Møller-Plesset methods. Comparison is made with coupled-cluster calculations that included single, double, and perturbatively applied triple excitations $(\operatorname{CCSD}(\mathrm{T}))$ and multiconfiguration quasi-degenerate perturbation theory ${ }^{47}$ (MCQDPT) calculations. The MCQDPT method is based on the secondorder perturbation treatment of the multiconfiguration selfconsistent field (MCSCF) wave function. The MCSCF wave function resulted from CAS $(12,12)$ calculations, i.e., the complete active space (CAS) with 12 electrons in 12 orbitals. The molecular orbitals (MOs) used in the CAS calculation were the 12 Hartree-Fock MOs with $\pi$ character. Only the configuration state functions (CSFs) that weighted more than $1.5 \times 10^{-4}$ in the MCSCF wave function were kept for the MCQDPT perturbation treatment. Test calculations showed that results were similar with smaller threshold values. The excited-state energy of the benzene dimer in the sandwich-like configuration was also calculated with the MCQDPT method. The MCQDPT calculations were performed with the GAMESS program, ${ }^{48}$ while the Gaussian03 program $^{49}$ was used for all of the other calculations.

The modified cc-pvdz basis set is used throughout this work. Basis set superposition errors (BSSEs) are computed with the counterpoise method of Boys and Bernardi. As stated above, it was shown ${ }^{42,46}$ that diffuse polarization functions are needed to obtain reliable correlation interaction energies. The hydrogen and carbon atom exponents of the $\mathrm{p}$ - and d-polarization functions, respectively, were set to $\alpha_{\mathrm{p}, \mathrm{H}}=0.15$ and $\alpha_{\mathrm{d}, \mathrm{C}}=$ 0.25 . $^{42}$ The maxima of the radial distribution functions of the original and the more diffuse d-polarization functions for the carbon atom are separated by $\Delta r=0.7981 \AA$. The nitrogen exponent, i.e., $\alpha_{\mathrm{d}, \mathrm{N}}$, was adjusted to reproduce the above $\Delta r$ shift between the original and the more diffuse d-polarization functions for the nitrogen atom. $\alpha_{\mathrm{d}, \mathrm{N}}$ is set here to 0.3236 .

Benzene Dimer. The long-range interaction energy between two phenyl substituents in polystyrene is approximated to that of two parallel benzene rings in rotation about a pseudo-carbon/ carbon bond. The configurations investigated in this work are representative of those in the polymer. This was achieved by considering structures where the benzene rings are attached to ghost backbone atoms, namely, $X_{1}$ and $X_{2}$ in Figure $2 b$. The structure of the benzene moiety was fixed to the experimental geometry used by Hobza et al. ${ }^{41,42}(\mathrm{CC}=1.406 \AA$ and $\mathrm{CH}=$ $1.08 \AA)$. Thus, the configuration of the benzene dimer is described by $R$ and $\varphi$, respectively, the distance between $\mathrm{X}_{1}$ and $\mathrm{X}_{2}$, and the dihedral angle about the $\mathrm{X}_{1}-\mathrm{X}_{2}$ bond. In 
TABLE 1: Energies (kcal/mol) of the Benzene Dimer at Various Geometries in the $S_{0}$ Ground State and in the $S_{1}$ State ${ }^{a}$

\begin{tabular}{|c|c|c|c|c|c|c|c|}
\hline \multirow[b]{2}{*}{$R(\AA)$} & \multirow{2}{*}{$\frac{\mathrm{S}_{0}, \varphi=0^{\circ}}{\operatorname{CCSD}(\mathrm{T})}$} & \multirow{2}{*}{$\frac{\mathrm{S}_{1}, \varphi=0^{\circ}}{\mathrm{MCQDPT}^{b}}$} & \multirow[b]{2}{*}{$\varphi(\mathrm{deg})$} & \multirow{2}{*}{$\frac{\mathrm{S}_{0}, R=3 \AA}{\operatorname{CCSD}(\mathrm{T})}$} & \multirow{2}{*}{$\frac{\mathrm{S}_{0}, R=4 \AA}{\operatorname{CCSD}(\mathrm{T})}$} & \multicolumn{2}{|c|}{$\mathrm{S}_{0}$} \\
\hline & & & & & & $\overline{R^{\prime}(\AA)}$ & $\overline{\mathrm{MP}^{c}}$ \\
\hline 3.0 & 14.59 & 97.55 & 0 & 14.59 & -1.00 & 3.916 & -0.09 \\
\hline 3.1 & 8.41 & 95.86 & 45 & 1.81 & -1.32 & 3.416 & -0.16 \\
\hline 3.3 & 3.04 & 94.22 & 90 & -1.15 & -0.89 & 2.916 & -0.26 \\
\hline 3.5 & 0.85 & 96.86 & 180 & -0.90 & -0.44 & 2.416 & -0.32 \\
\hline 4.0 & -1.00 & 99.57 & & & & 1.916 & 0.35 \\
\hline 10.0 & 0.0 & 102.29 & & & & 1.416 & 5.28 \\
\hline & & & & & & 0.916 & 35.32 \\
\hline
\end{tabular}

${ }^{a}$ See Figure 4 for definition of $R$ and $\varphi$, and see Figure 7 for $R^{\prime}$. Energies are corrected for BSSE. ${ }^{b}$ The BSSE correction is chosen to fit the experimental dissociation energy of the benzene dimer in the excimer configuration (see text). For $R=10.0 \AA$, the $\mathrm{S}_{1}$ state is $102.29 \mathrm{kcal} / \mathrm{mol}$ above the ground state in the same configuration. ${ }^{c}$ The BSSE is computed at the MP2 level.

this figure, $R_{x}$ is a parameter and is set to $1.5 \AA$, like the respective $\mathrm{CC}$ bond in the polymer.

Energies of the benzene dimer are given in Table 1 and plotted in Figure 3. ${ }^{50}$ The energies of the sandwich-like structure are presented in Figure 3a versus the intermolecular distance $R$. In Figures $3 \mathrm{~b}$ and $3 \mathrm{c}$, one benzene ring undergoes rotation about the $X_{1}-X_{2}$ ghost bond (Figure $2 b$ ) while the other ring is held fixed. The intermolecular distance is constant at $R=3$ $\AA$ (Figure 3b) and $R=4 \AA$ (Figure 3c). These distances are representative of those in the macromolecule. The CCSD(T) results are bracketed by the MP2 and MP4(SDQ) calculations. The larger part of the MP4(SDQ) energy is accounted for by the repulsive third-order correction. (The SDQ contribution is attractive and of smaller amplitude.) The triple contribution being of attractive nature, the $\operatorname{CCSD}(\mathrm{T})$ results are lower than the MP4(SDQ) energy. Thus, reliable ground-state energies of aromatic dimers may be obtained from MP2 and/or MP4(SDQ) calculations when $\operatorname{CCSD}(\mathrm{T})$ calculations are prohibited by the size of the system (e.g., the carbazole dimer). Second, close examination of Figure 3 shows that a slight rotation about the $\mathrm{X}_{1}-\mathrm{X}_{2}$ bond stabilizes the system. Thus, the sandwich-like structure is not a local minimum in the ground state. This effect is similar to that observed between the sandwich-like structure and the parallel-displaced geometry of the benzene dimer. ${ }^{42}$

Finally, it is quite interesting to note that the BSSE is independent of the method of calculation (Figure 3, dotted lines). This point is used below to correct MCQDPT energies for BSSE.

The MCQDPT method is not size consistent, and the computation of the BSSE cannot be performed with the counterpoise method. However, since the BSSE is independent of the method of calculation (Figure 3), the MCQDPT energies are corrected with the CCSD(T) BSSEs. The results shown in Figure $3 \mathrm{a}$ (bold solid line) are in excellent agreement with the CCSD(T) results. Thus, the same level of calculation was used to compute energies for the first excited state $\mathrm{S}_{1}$. In the $D_{6 h}$ point group, this $\mathrm{S}_{1}$ state is of $\mathrm{B}_{1 \mathrm{~g}}$ symmetry. $\left(C_{6}(z)\right.$ is assumed with the $x$-axis through the carbon atoms.) However, in the $S_{1}$ state, the magnitude of the BSSE may differ significantly from that in the ground state. Thus the BSSE of the ground state was scaled until the corrected energy reproduced the experimental excimer interaction energy of $8.1 \mathrm{kcal} / \mathrm{mol} .^{51}$ This scaling factor is 2.134. MCQDPT calculations at geometries where one phenyl ring is rotated about the pseudo $X_{1}-X_{2}$ bond were not attempted because in the $C_{2}$ symmetry virtual canonical $\pi$ MOs were strongly mixed. The modified virtual orbital (MVO) procedure, based on the diagonalization of the Fock operator of a very positive ion within the virtual space only, did not improve the starting SCF orbitals. In Figures $3 b$ and $3 c$, excited-state data are plotted from the analytic potential derived here (see below and Table 2). Interestingly, the above procedure yielded an intermolecular distance of $3.3 \AA$ at the minimum in the $S_{1}$ state, in excellent agreement with that deduced from fluorescence spectra of concentrated solutions of benzene. ${ }^{24,51,52}$ Furthermore, the maximum of excimer emission in steady-state fluorescence experiments of polystyrene in dilute solutions is located at $335 \mathrm{~nm},{ }^{52}$ i.e., a transition of $85.3 \mathrm{kcal} / \mathrm{mol}$. PariserParr-Pople calculations ${ }^{53}$ have shown that excimers in PS are separated by $3.1 \AA .{ }^{54}$ The difference between the $S_{1}$ and the $S_{0}$ states for $R=3.1 \AA$ is $87.5 \mathrm{kcal} / \mathrm{mol}$ (Table 1), in good agreement with the above experimental data. Finally, the singlet absorption spectra of [2,2] and [3,3] paracyclophanes shows transitions at 32800 and $34000 \mathrm{~cm}^{-1}, 55$ respectively, i.e., 93.8 and $97.2 \mathrm{kcal} / \mathrm{mol}$, thus a difference of $3.4 \mathrm{kcal} / \mathrm{mol}$. The meanplane separations of $3.1 \AA[2,2]$ and $3.3 \AA[3,3]$ were determined experimentally. ${ }^{56,57}$ This is in excellent agreement with the value of $3.7 \mathrm{kcal} / \mathrm{mol}$ obtained from our MCQDPT calculations in Table 1.

In addition, the $\sigma$ repulsive interaction between chromophores that belonged to different macromolecules was calculated at the MP2 level of theory (Table 1). The model system is represented in Figure 4a. Two coplanar benzene molecules are separated by $R^{\prime}$, the distance between hydrogen atoms $\mathrm{H}_{1}$ and $\mathrm{H}_{1}{ }^{\prime}$. Some additional single-point $\operatorname{CCSD}(\mathrm{T})$ calculations were performed. We found that $90 \%$ of the $\operatorname{CCSD}(\mathrm{T})$ energy was obtained at the MP2 level, and it was decided to use MP2 energies in this part. In this configuration, the energy arises from $\sigma$ repulsions between hydrogen atoms that do not participate in the excitation process. Thus, in the fitting procedure below, this interaction was kept the same in the $\mathrm{S}_{0}$ and $\mathrm{S}_{1}$ states. The two data sets in Table $1\left(\mathrm{~S}_{0}\right.$ and $\left.\mathrm{S}_{1}\right)$ were fit separately with the sum of two-body 12-6 Lennard-Jones potentials. The sixthpower combination rule was used for cross-terms. Parameters are given in Table 2 .

At this point, the torsion potential energy about the backbone and the interactions with other neighboring phenyl substituents are not taken into account. These issues are examined in the Molecular Dynamics section.

Carbazole Dimer. Ground State. MP2 calculations were performed for the carbazole dimer in the ground state. The geometry of each carbazole unit was fixed to the experimental crystal structure ${ }^{58}$ while their relative orientation was allowed to change. $R$ and $\varphi$ are defined in Figure 2, except phenyl rings are replaced by carbazyl units. In this Figure, 1 and $1^{\prime}$ become nitrogen atoms. These calculations were scaled to estimate CCSD(T) energies. First, the MP2 energy of the benzene dimer in the ground state and sandwich-like geometries, i.e., $V(R, \varphi$ $\left.=0^{\circ}\right)$, was fit with the Morse potential $V_{1}=D_{1}(1-\exp (-\beta(R$ $\left.\left.\left.-r_{01}\right)\right)\right)^{2}-D_{1}$. The $\operatorname{CCSD}(\mathrm{T})$ energy was fit with $V_{2}=D_{2}(1$ $\left.-\exp \left(-\beta\left(R-r_{02}\right)\right)\right)^{2}-D_{2}$, where the $\beta$ parameter was kept fixed at the value found previously. The MP2 energy of the carbazole dimer was fit with $V_{3}=D_{3}\left(1-\exp \left(-\beta^{\prime}\left(R-r_{03}\right)\right)\right)^{2}$ 

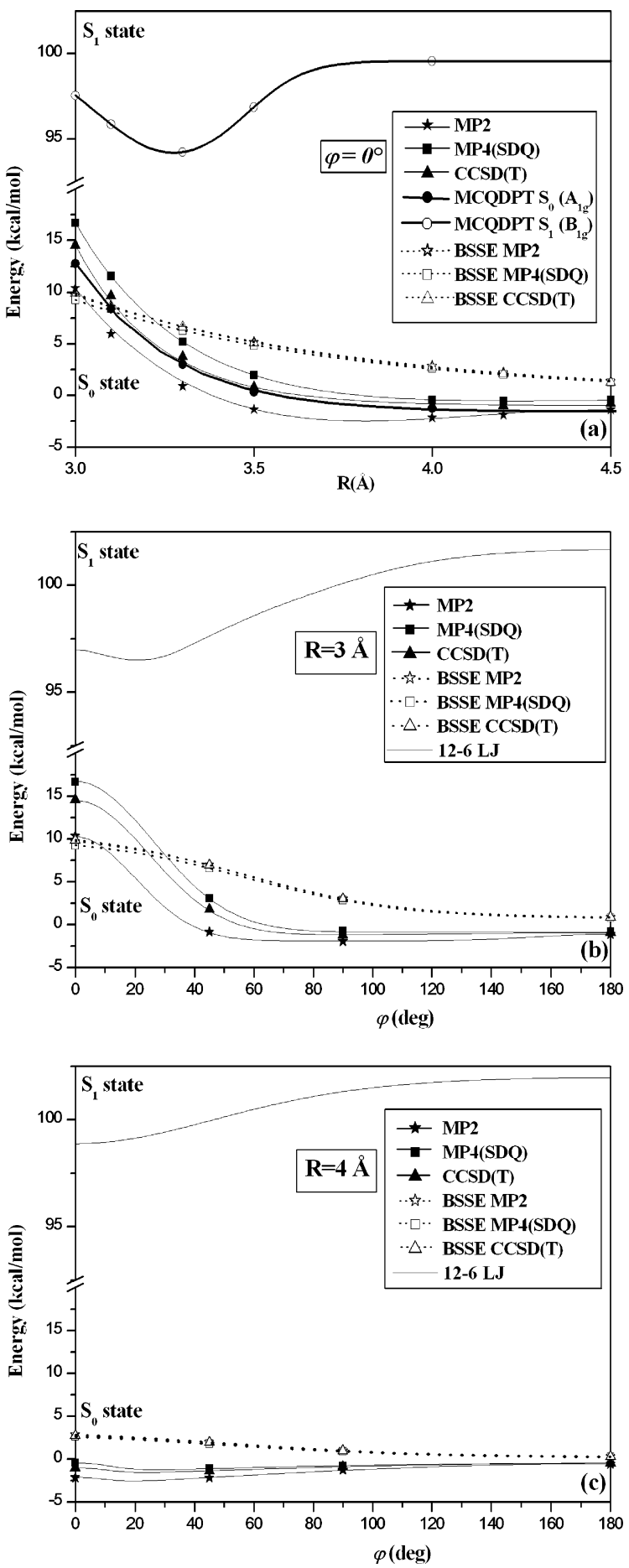

Figure 3. Ground-state and excited-state energy calculations with the modified cc-pvdz basis set for the benzene dimer in the (a) sandwichlike geometry $\left(\varphi=0^{\circ}\right)$ and (b and c) versus $\varphi$ rotation about the ghost $\mathrm{X}_{1}-\mathrm{X}_{2}$ bond (Figure 2). Intermolecular distance is held fixed at (b) 3 $\AA$ or (c) $4 \AA$. The geometry of each benzene fragment is held fixed at the experimental geometry, and the energies are corrected for BSSE. The BSSE is indicated for the ground state (see text). Lines are only a guide to the eye. In addition, the $12-6 \mathrm{LJ}$ potential $\left(\mathrm{S}_{1}\right.$ state, Table 2) is also shown.

$-D_{3}$, and the estimated CCSD(T) energy of the carbazole dimer was given by $V_{4}=D_{4}\left(1-\exp \left(-\beta^{\prime}\left(R-r_{04}\right)\right)\right)^{2}-D_{4}$, with $D_{4}$ $=D_{2} D_{3} / D_{1}$, and $r_{04}=r_{03}+r_{02}-r_{01}$. Fitted parameters are $D_{1}$ $=2.228 \mathrm{kcal} / \mathrm{mol}, \beta=1.454 \AA^{-1}, r_{01}=3.837 \AA, D_{2}=1.020$ $\mathrm{kcal} / \mathrm{mol}, r_{02}=4.094 \AA, D_{3}=7.548 \mathrm{kcal} / \mathrm{mol}, \beta^{\prime}=1.447 \AA^{-1}$, $r_{03}=3.672 \AA, D_{4}=3.457 \mathrm{kcal} / \mathrm{mol}$, and $r_{04}=3.929 \AA$, and results are shown in Figure 5a. A similar procedure was used
TABLE 2: 12-6 Lennard-Jones Potential Parameters for Chromophore Atoms in Polystyrene (PS) and Poly $\left(N\right.$-vinylcarbazole) (PVK) in the $S_{0}$ and the $S_{1}$ States ${ }^{a}$

\begin{tabular}{lllll}
\hline & \multicolumn{2}{c}{$\mathrm{S}_{0}$} & \multicolumn{3}{c}{$\mathrm{S}_{1}$} \\
\cline { 2 - 3 } \cline { 4 - 5 } & \multicolumn{1}{c}{$\epsilon_{i}$} & $\mathrm{r}_{\mathrm{i}}$ & \multicolumn{2}{c}{$\epsilon_{i}$} \\
\hline \multicolumn{5}{c}{ PS Phenyl Atoms } \\
$\mathrm{C}$ & $3.528 \times 10^{-2}$ & 4.2270 & 0.2399 \\
$\mathrm{H}$ & $2.173 \times 10^{-2}$ & 1.6390 & $1.678 \times 10^{-4}$ & 3.4112 \\
\multicolumn{5}{c}{ PVK Carbazyl Atoms } \\
$\mathrm{N}$ & 0.5000 & 4.2674 & 0.5 \\
$\mathrm{C}$ & $3.544 \times 10^{-2}$ & 3.5000 & 0.2194 & 4.2744 \\
$\mathrm{H}$ & $10^{-3}$ & 3.0000 & $1.281 \times 10^{-3}$ & 3.0861 \\
& & &
\end{tabular}

${ }^{a}$ Units are in $\mathrm{kcal} / \mathrm{mol}$ and angstroms. $V_{i j}=\epsilon_{i j}\left[\left(r_{i j} / r\right)^{12}-2\left(r_{i j} / r\right)^{6}\right]$. The sixth-power combination rule is used in this work, i.e., $\epsilon_{i j}=$ $2 \sqrt{\left(\epsilon_{i} \epsilon_{j}\right)} \times\left[r_{i}^{3} r_{j}^{3} /\left(r_{i}^{6}+r_{j}^{6}\right)\right]$ and $r_{i j}^{6}=0.5\left(r_{i}^{6}+r_{j}^{6}\right)$.

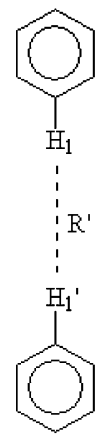

(a)

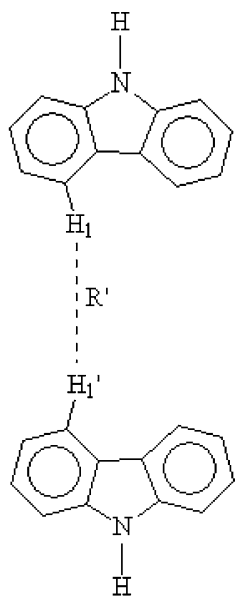

(b)
Figure 4. Configurations of the coplanar (a) benzene dimer and (b) carbazole dimer.

to scale the energy of the carbazole dimer in the ground state and for rotated structures about the pseudo $X_{1}-X_{2}$ bond, i.e., $V(R=3 \AA, \varphi)$ and $V(R=4 \AA, \varphi)$. First, the difference between $\operatorname{CCSD}(\mathrm{T})$ and MP2 energies for the benzene dimer was fit to a Gaussian function $\Delta V_{1}=\left(A_{1} / w \sqrt{ } \pi / 2\right) \exp \left(-2(\varphi / w)^{2}\right)$ for $R=$ $3 \AA$. This difference was fit for $R=4 \AA$ with $\Delta V_{2}=\left(A_{2} / w \sqrt{ } \pi\right)$ 2) $\exp \left(-2(\varphi / w)^{2}\right)$, where $w$ was kept fixed at the value found previously. Similarly, $\Delta V_{3}=\left(A_{3} / w \sqrt{ } \pi / 2\right) \exp \left(-2(\varphi / w)^{2}\right)$ and $\Delta V_{4}=\left(A_{4} / w \sqrt{ } \pi / 2\right) \exp \left(-2(\varphi / w)^{2}\right)$ represented this difference for the carbazole dimer for $R=3 \AA$ and $R=4 \AA$, respectively. $A_{3}$ and $A_{4}$ were chosen to reproduce the estimated CCSD(T) energy computed above for $\varphi=0^{\circ}$ (i.e., the sandwich-like configuration). Fit parameters are $w=100^{\circ}, A_{1}=526.392$ $\mathrm{kcal} / \mathrm{mol}, A_{2}=144.131 \mathrm{kcal} / \mathrm{mol}, A_{3}=1444.048 \mathrm{kcal} / \mathrm{mol}$, and $A_{4}=380.486 \mathrm{kcal} / \mathrm{mol}$. The estimated CCSD $(\mathrm{T})$ energies $V_{\mathrm{MP} 2}$ $+\Delta V_{i}$ are plotted in Figure $5 \mathrm{~b}$ for $R=3 \AA$ and Figure $5 \mathrm{c}$ for $R=4 \AA$.

In addition, a single-point calculation for the carbazole exciplex configuration $\left(R=3.1 \AA, \varphi=65^{\circ}\right)$ yielded -2.23 $\mathrm{kcal} / \mathrm{mol}$ at the $\operatorname{CCSD}(\mathrm{T})$ level. This data point is used below to estimate the excited-state potential of the carbazole dimer.

Last, the $\sigma$ repulsive interaction between consecutive chromophores that belonged to different molecules was computed at the MP2 level. The model system is represented in Figure 4b. In this figure, the coplanar carbazole molecules are separated by $R^{\prime}$, the distance between hydrogen atoms $\mathrm{H}_{1}$ and $\mathrm{H}_{1}{ }^{\prime}$. Results are given in Table 3. Moreover, in the fitting procedure and for reasons stated above, this interaction was assumed to be the same in the $S_{0}$ and $S_{1}$ states. 

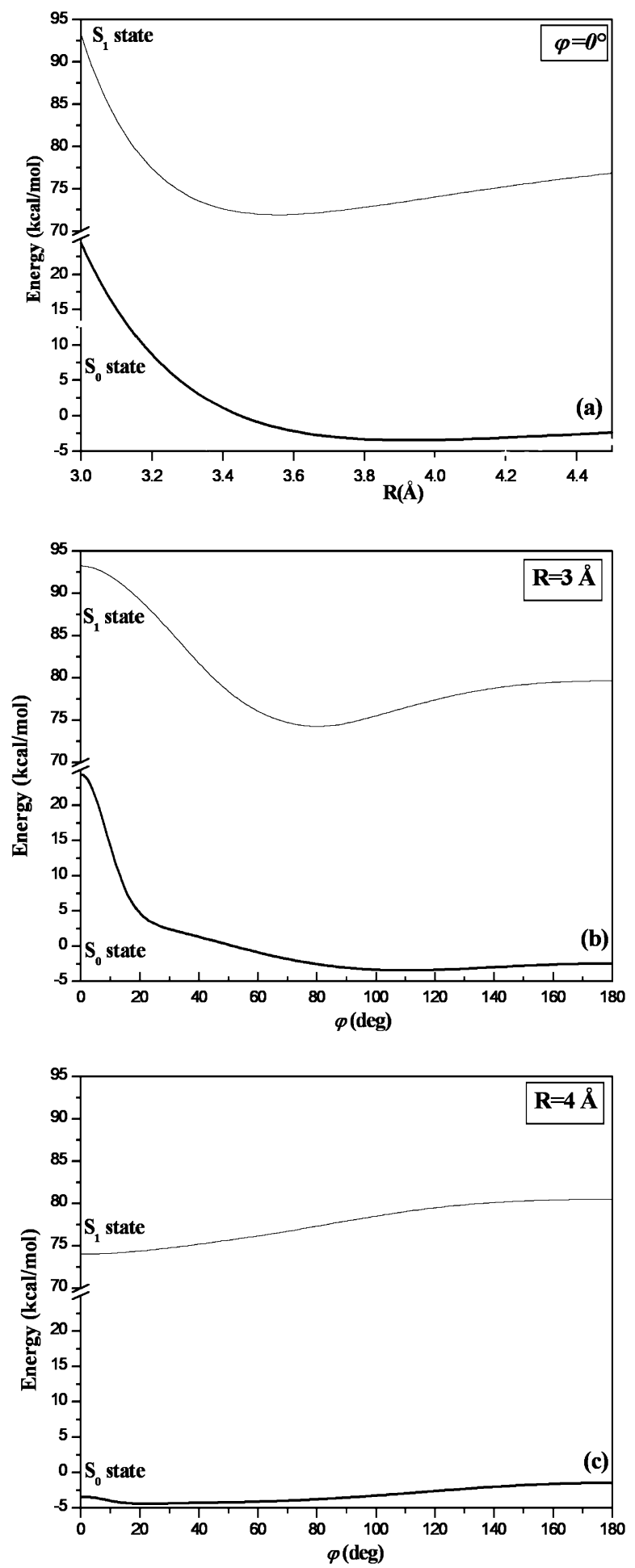

Figure 5. Interaction energy of the carbazole dimer in the $S_{0}$ and the $S_{1}$ states: (a) sandwich-like configuration; ( $b$ and c) rotated structures about the pseudo $\mathrm{X}_{1}-\mathrm{X}_{2}$ bond (Figure 2) and for fixed intermolecular distance $R$.

Excited State. The very large number of CSFs for the carbazole dimer prohibited calculations with the MCQDPT method. Instead, in light of the good agreement obtained between the results presented above for PS and experimental data, the excited-state potential energy was estimated at three specific geometries from both experimental fluorescence results and the ground-state calculations reported above. First, in dilute solution, monomer emission occurs at $350 \mathrm{~nm}$, i.e., $81.7 \mathrm{kcal} /$ mol above the ground state. ${ }^{14,15}$ Second, the fully overlapped excimer emits at $420 \mathrm{~nm}(68.1 \mathrm{kcal} / \mathrm{mol}) .^{3,13-15}$ Considering
TABLE 3: Energies (kcal/mol) of the Coplanar Carbazole Dimer in the $\mathbf{S}_{\mathbf{0}}$ State $^{a}$

\begin{tabular}{cr}
\hline$R^{\prime}(\AA)$ & $\mathrm{MP}^{\mathrm{b}}$ \\
\hline 0.977 & 66.66 \\
1.477 & 8.51 \\
1.977 & -0.47 \\
2.477 & -1.26 \\
2.977 & -0.90 \\
3.477 & -0.57 \\
3.977 & -0.36 \\
4.477 & -0.24 \\
4.977 & -0.17
\end{tabular}

${ }^{a}$ See Figure 7 for the definition of $R^{\prime}$. Energies are corrected for BSSE. ${ }^{b}$ The BSSE is computed at the MP2 level.

that carbazyl units, like phenyl substituents in polystyrene, ${ }^{53}$ are separated by $3.1 \AA$ in the sandwich-like configuration, the fully overlapped excimer is $1.52 \mathrm{kcal} / \mathrm{mol}$ above infinitely separated carbazole moieties in the excited state. Third, the partially overlapped structure $\left(\varphi=65^{\circ}\right)$, the so-called exciplex, was recorded in fluorescence spectra at $375 \mathrm{~nm}(76.2 \mathrm{kcal} / \mathrm{mol})$. Provided carbazyl rings are separated by $R=3.1 \AA$ like excimers in PS, this structure stands $7.7 \mathrm{kcal} / \mathrm{mol}$ below infinitely separated carbazole units in the excited state.

The above results $\left(S_{0}\right.$ and $S_{1}$ states) were fit with the sum of two-body 12-6 Lennard-Jones potentials. Parameters are given in Table 2.

\section{Molecular Dynamics Simulations of Polystyrene}

Computational Methods. The all-atom model was used in this work, and the molecular chains consisted of 20 monomer units for a total of 100 units in the periodic cubic cell. The size of the cell was set to $25.43 \AA$ for PS and $29.91 \AA$ for PVK, to match the experimental density at $T=298 \mathrm{~K}$. The MD simulations were performed with the velocity Verlet integrator ${ }^{59}$ and NVT Berendsen thermostat. ${ }^{60}$ Periodic boundary conditions were applied. Initial configurations were obtained from the Theodorou-Suter chain generation ${ }^{61}$ at room temperature. This procedure is based on the rotational isomeric state (RIS) theory. The effect of nonbonded interactions is included into this scheme to account for bulk packing requirements. The simulations were performed with the Materials Studio program. ${ }^{62}$

The cell was equilibrated on the ground-state surface for 100 ps with a time step of $1 \mathrm{fs}$. Then, the simulation was run for 1 ns with the Rattle algorithm ${ }^{63}$ for bond constraints and a time step of 2 fs. The last frame of the ground-state trajectory was used to start the excited-state trajectory. The latter simulation ran for $1 \mathrm{~ns}$, with a time step of 2 fs and the Rattle algorithm. The underlying hypothesis in this procedure is that all the dyads go through the $\mathrm{S}_{0} \leftrightarrow \mathrm{S}_{1}$ excitation/emission process.

The CFF93 force field used in this work is intended for applications to polymers and organic materials. ${ }^{64}$ The long-range interactions between aromatic nitrogen, carbon, and hydrogen atoms were replaced by the $12-6$ Lennard-Jones $(\mathrm{LJ})$ potentials derived in this work (Table 2). Partial charges were set to zero.

Polystyrene. Only isotactic polystyrene is investigated in this section. In this work, we are interested with the local conformation change that takes place when a dyad is excited to the $S_{1}$ level. It is expected that chromophores in the excimer state are separated by $3.1 \AA$. Thus, analytic potentials need to represent accurately this phase space region. In Figure 6 , the $\mathrm{LJ}$ potential derived in this work for the $S_{0}$ state is compared with reference analytic potentials. ${ }^{20,65}$ The latter are widely used for groundstate simulations of polystyrene. The sandwich-like configurations are shown in Figure 6a, while rotated structures about the 

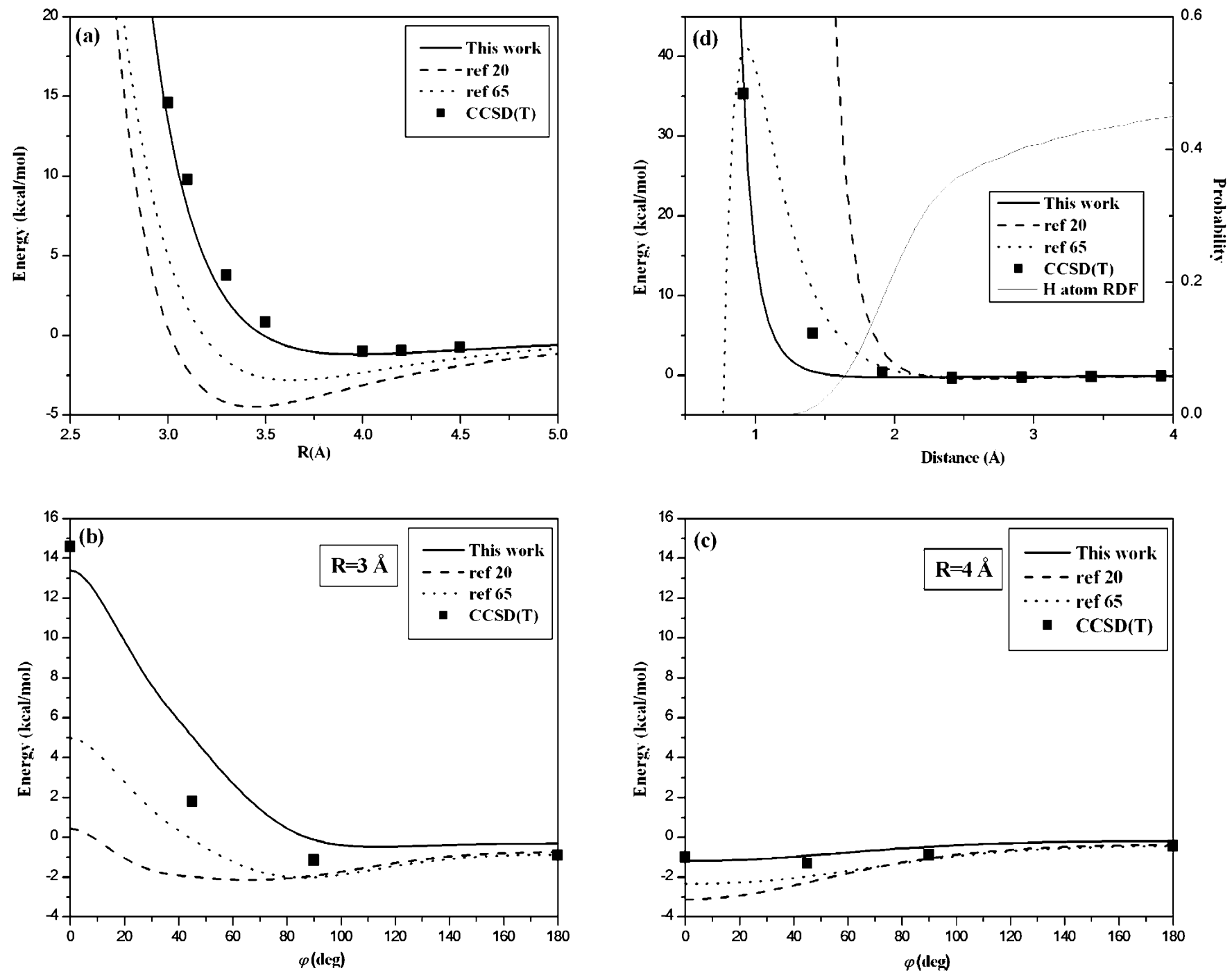

Figure 6. Comparison of the analytic potential derived in this work for the $S_{0}$ state with literature data (refs 20 and 65): (a) sandwich-like configuration; (b and c) rotated structures about the pseudo $\mathrm{X}_{1}-\mathrm{X}_{2}$ bond (Figure 2) and for fixed intermolecular distance $R$; (d) hydrogen atom radial distribution function calculated from MD simulations of PS in the ground state.

pseudo $\mathrm{X}_{1}-\mathrm{X}_{2}$ bond (Figure $2 \mathrm{~b}$ ) are represented in Figure $6 \mathrm{~b}$ $(R=3 \AA)$ and Figure $6 \mathrm{c}(R=4 \AA)$. Discrepancy is significant for short-range distances and sandwich-like geometries, as is most clearly seen in Figure $6 \mathrm{~b}$ for $\varphi=0^{\circ}$. In Figure $6 \mathrm{~d}$ (lefthand-side scale), the interaction energy of coplanar benzene molecules is plotted versus $R^{\prime}$ (see definition in Figure 4a). In addition, the intermolecular hydrogen atom radial distribution function (RDF) was calculated from our ground-state MD simulation and plotted in Figure 6d (right-hand-side scale). For short intermolecular distances $R^{\prime}$, the exp6+charge model ${ }^{65}$ is of attractive nature and the $12-6 \mathrm{LJ}$ potential from ref 20 is too repulsive. However, in the short range $\left(R^{\prime}<2 \AA\right)$, the hydrogen atom RDF is small, and the wrong behavior of the above potentials becomes unimportant.

Next, consider (1) the distance $d$ that joins the center of mass of two planar consecutive phenyl rings and (2) the unit vectors $\overrightarrow{\mathbf{u}}_{1}$ and $\overrightarrow{\mathbf{u}}_{2}$ perpendicular to these planes. The average projection of $d$ onto $\overrightarrow{\mathbf{u}}_{1}$ and $\overrightarrow{\mathbf{u}}_{2}$ yields the mean distance between consecutive phenyl rings. The distribution of $d$ is plotted in Figure 7 for the $S_{0}$ and $S_{1}$ states and for configurations where $\varphi<60^{\circ}$. The distribution of $\varphi$ (see insert in Figure 7) is clearly separated into two distinct sets, as expected. In excimer-like configurations, $\varphi$ is necessarily smaller than $60^{\circ}$. The distribution of the mean distance between consecutive phenyl rings

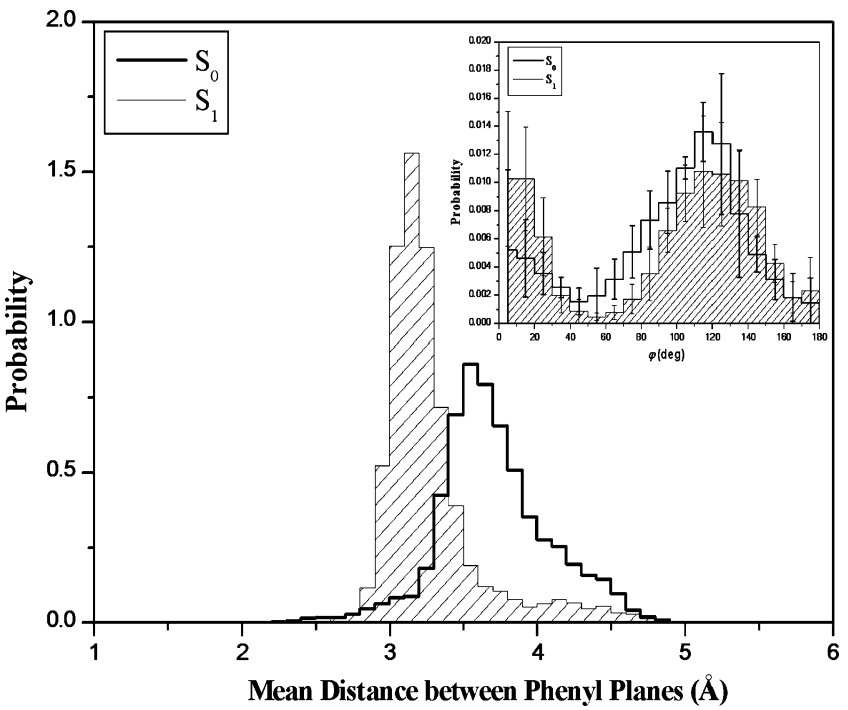

Figure 7. Normal distribution of the mean distance between consecutive phenyl rings. In this figure, only the dyads with $\varphi<30^{\circ}$ (Figure 2 ) are represented. Standard deviations are not shown for clarity. The insert in this figure is the overall distribution of $\varphi$ angles for the last $200 \mathrm{ps}$ of the simulation. See text for the calculation of standard deviations. 

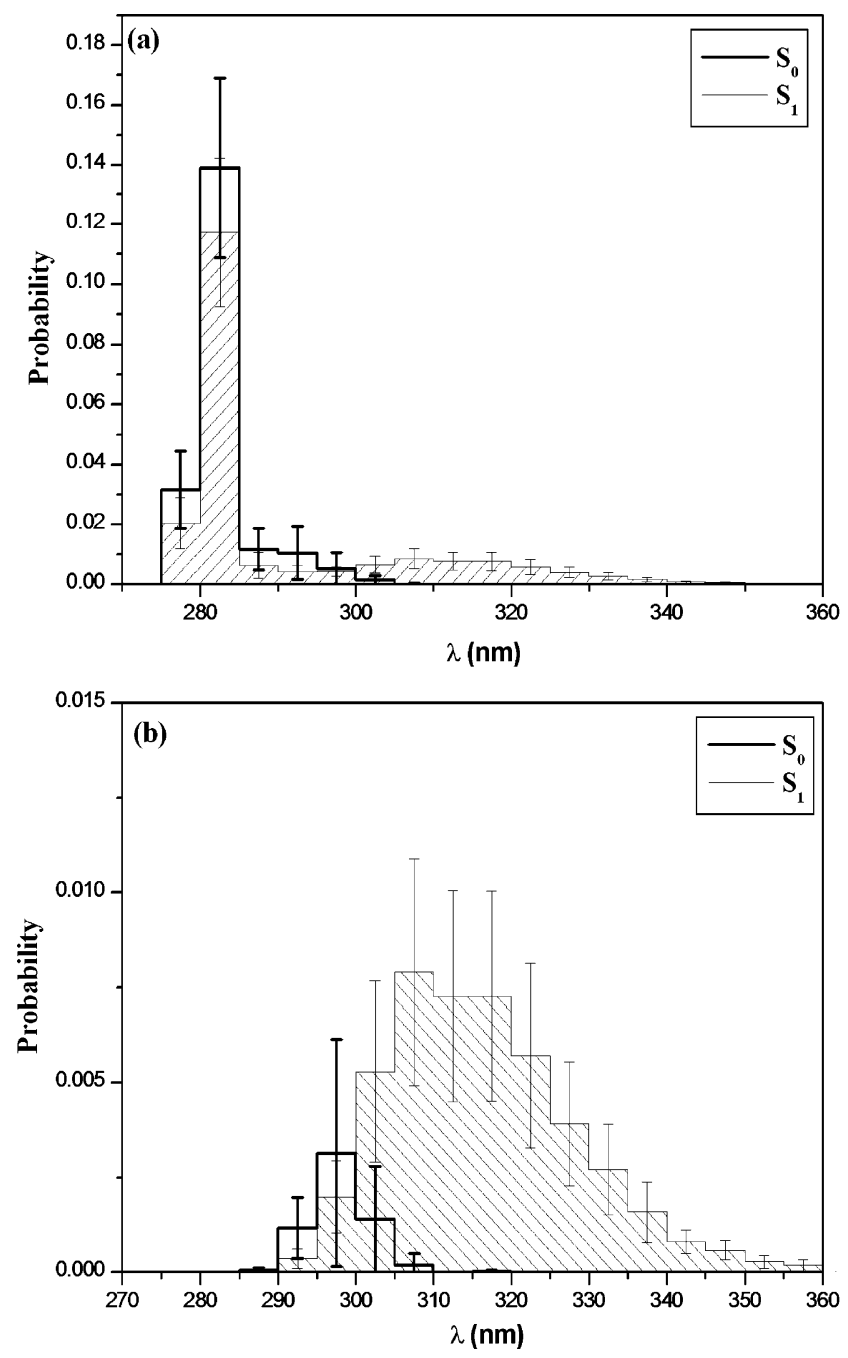

Figure 8. (a) Simulated excitation $\left(\mathrm{S}_{0}\right)$ and fluorescence emission $\left(\mathrm{S}_{1}\right)$ spectra. Probabilities are normalized. (b) Contribution of excimer configurations from the simulated spectra in part a.

TABLE 4: Proportion of Excimer and Exciplex Configurations $^{a}$

\begin{tabular}{|c|c|c|c|c|c|}
\hline \multicolumn{2}{|c|}{ meso24 } & \multicolumn{2}{|c|}{ meso10 } & \multicolumn{2}{|c|}{ racemic } \\
\hline excimer & exciplex & excimer & exciplex & excimer & exciplex \\
\hline $23.8 \%$ & $13.3 \%$ & $10.4 \%$ & $12.2 \%$ & $4.6 \%$ & $9.4 \%$ \\
\hline $25.2 \%$ & $7.1 \%$ & $13.0 \%$ & $10.7 \%$ & $11.9 \%$ & $4.0 \%$ \\
\hline
\end{tabular}

${ }^{a}$ Results are averaged over the final 200 ps of the respective trajectory $\left(\mathrm{S}_{0}\right.$ or $\left.\mathrm{S}_{1}\right)$. In the ground state, the dyads are in excimer-like or exciplex-like configurations.

shows that tighter structures are obtained in the $S_{1}$ state. The peak at $3.5 \AA$ ( $\mathrm{S}_{0}$ state) shifts to $3.1 \AA$ in the $\mathrm{S}_{1}$ state, as expected from the experimental data discussed previously. It is interesting to note that the excimer configuration minimum is located at $R$ $=3.3 \AA$ for benzene, while it is $3.1 \AA$ in condensed media. Thus, in PS, this tightening is not due solely to the intramolecular nonbonded interactions but to the concerted action of the intramolecular, intermolecular, and polymer backbone torsion interactions as well. This effect is also seen for PVK, although less significant, as shown below.

Finally, the correlation between structure and experimental spectra is pursued. The local dyadic structure is related to the excitation spectrum in the $\mathrm{S}_{0}$ state, while correlation is made with the fluorescence emission spectrum in the $S_{1}$ state. First, consider one set of consecutive chromophores. If a Franck-
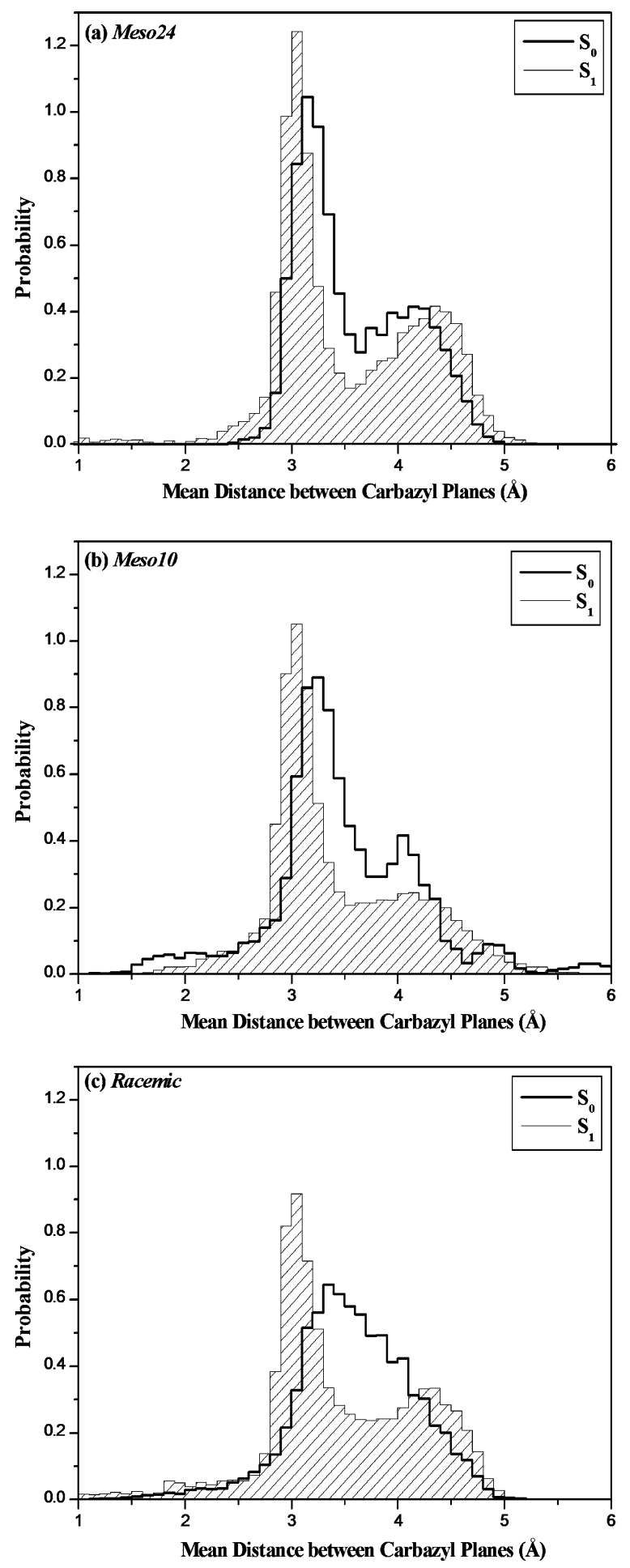

Figure 9. Normal distribution of the mean distance between carbazyl planes in ( $a$ and $b$ ) isotactic and (c) syndiotactic polymers. In part a, the ratio of excimer-like configurations is $23.8 \%$, while it is $10.4 \%$ in part b (Table 4). Standard deviations are not shown for clarity. These results were averaged over the last $200 \mathrm{ps}$ of the ground-state simulation.

Condon transition is assumed between fundamental vibrational levels, then the transition wavelength $\lambda$ for this dyad can be deduced from the analytic potential energy of the $S_{0}$ and $S_{1}$ states. The $\lambda$ distribution per macromolecule was recorded for the last 200 ps of the simulation. Averaging was performed over molecules in the cell, thus yielding the mean distribution and standard deviations. In Figure 8a, the excitation spectrum (bold solid) and the fluorescence emission spectrum (solid) are plotted 

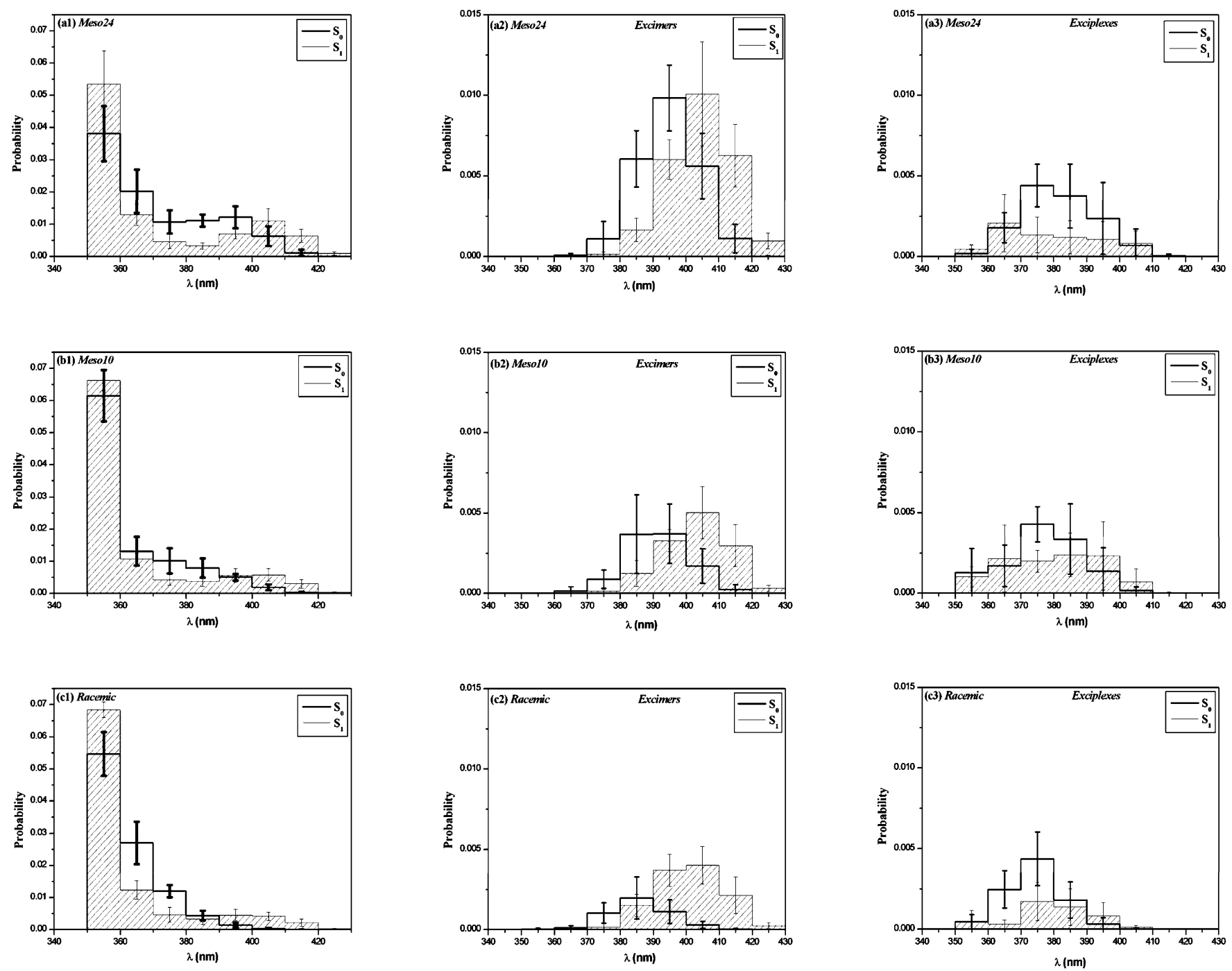

Figure 10. (a1, b1, and c1) Simulated excitation $\left(\mathrm{S}_{0}\right)$ and fluorescence emission $\left(\mathrm{S}_{1}\right)$ spectra of the polymers investigated in this work, i.e., meso24, meso10, and racemic (see text). (a2, b2, and c2) Contribution of excimers from the spectra in part a. (a3, b3, and c3) Contribution of exciplexes from the spectra in part a.

according to the above procedure. The sharp peak at $280 \mathrm{~nm}$ is characteristic of monomer-like transitions. Thus, most dyads are not in excimer-like geometries. However, this transition is hardly seen in fluorescence experiments, partly because of selfabsorption effects. ${ }^{6}$ Nevertheless, excimer states are clearly favored in the $S_{1}$ state $(\lambda>290 \mathrm{~nm})$.

The contribution of excimer-like geometries $\left(\mathrm{S}_{0}\right)$ and excimers $\left(\mathrm{S}_{1}\right)$ from the spectra in Figure $8 \mathrm{a}$ is plotted in Figure $8 \mathrm{~b}$. These dyads were selected according to the criteria $d<3.5 \AA$ and $\varphi<30^{\circ}$, and the angle between the phenyl planes is less than $45^{\circ}$ or larger than $135^{\circ}$ to ensure face-to-face planar configurations. This angle is $0^{\circ}$ (or $180^{\circ}$ ) for the perfect sandwich-like configuration. Only $3 \%$ of the meso dyads are in an excimer-like configuration in the $\mathrm{S}_{0}$ state, while this fraction goes up to $23 \%$ in the $\mathrm{S}_{1}$ state. The mean distance shift (from 3.5 to $3.1 \AA$ ) between the phenyl planes in Figure 7 can be directly related to the wavelength shift in Figure $8 \mathrm{~b}$. In the excited state, the mean distance between the phenyl rings is $3.1 \AA$, while it is $3.5 \AA$ in the ground state. Thus, smaller wavelengths are obtained (Figure $3 a$ ). In addition, the distribution of $\varphi$ is directly correlated to the distribution of $\lambda$ in Figure 8b. As shown in Figures $3 b$ and 3c, energy varies smoothly with respect to $\varphi$ for $R=3.5 \AA$. This is why, in Figure 8b, the distribution of wavelengths is thin in the $\mathrm{S}_{0}$ state. The opposite is expected for $R=3.1 \AA$, and a wide distribution of $\lambda$ is obtained in the $S_{1}$ state.

Poly( $N$-vinylcarbazole). PVK shows more complex structures than PS because full and partial overlaps between consecutive chromophores, respectively, excimers and exciplexes, are observed in experimental fluorescence spectra. In this work, a dyad is considered in excimer (or excimer-like) configuration when (1) the mean distance between the carbazyl planes is between 2.7 and $3.5 \AA$, (2) $0^{\circ}<\varphi<30^{\circ}$, and (3) the angle between the carbazyl planes is smaller than $45^{\circ}$ or larger than $135^{\circ}$. A dyad is considered in exciplex (or exciplex-like) configuration when conditions 1 and 3 above are fulfilled and condition 2 is replaced by $30^{\circ}<\varphi<90^{\circ}$. We recall that a perfect exciplex is obtained for $\varphi=65^{\circ}$. Finally, excimer and exciplex configurations were recorded for the last 200 ps of the simulations in the $S_{0}$ and $S_{1}$ states. Isotactic and syndiotactic polymers, i.e., consecutive sets of meso and racemic dyads, respectively, are investigated here. In addition, two sets of isotactic PVK were prepared. One was obtained according to the procedure described above at $T=298 \mathrm{~K}$ (Computational Section). The other was generated with the Theodorou-Suter chain model at $T=50 \mathrm{~K} .10 .4 \%$ and $23.8 \%$ of the dyads, respectively, were in excimer-like configurations at the end of the ground-state simulation. The respective sets are labeled 
below meso10 and meso24. It dropped to $4.6 \%$ for racemic PVK. The population of excimers and exciplexes in the $S_{0}$ and $\mathrm{S}_{1}$ states are presented in Table 4. As expected, excimers are favored in the $S_{1}$ state. This effect is most significant for the racemic dyads. However, in every case, the exciplex population is less in the $S_{1}$ state than that in the ground state. These results are analyzed in Figures 9 and 10.

The normalized distribution of the mean distance between consecutive carbazyl rings is plotted in Figure 9. These graphs are averaged over the last 200 ps of the trajectories. The two isotactic sets, i.e., meso 24 and meso 10 follow similar bimodal distributions, a characteristic of excimer-like and excimer configurations. On the contrary, in the ground state, the racemic sample (Figure 9c) exhibits a bell-shaped distribution centered on $3.5 \AA$. In this state, the excimer-like configurations represent only $4.6 \%$ of the dyads. The gauche effect in the isotactic polymers favors helicoidal structures where the substituents are slightly displaced from one another $\left(\varphi_{1}=+60^{\circ}\right.$ and $\varphi_{2}=-60^{\circ}$, Figure 2a). In this configuration, excimer-like dyads are favored. Contrarily, for syndiotactic polymers, $\varphi_{1}$ and $\varphi_{2}$ are evenly distributed $\left(\varphi_{1}= \pm 60^{\circ}\right.$ and $\left.\varphi_{2}= \pm 60^{\circ}\right)$ and excimer-like dyads are not favored. This effect is clearly enhanced in simulations of a single PVK macromolecule. In this case, the population of excimers in the $S_{1}$ state is $72 \%$ and $22 \%$ for the isotactic and, respectively, syndiotactic PVK. Nevertheless, in the excited state and in condensed media, all of the distributions are similar and bimodal (Figure 9), thus giving evidence for a significant population of excimers. This is because the van der Waals interaction becomes more important than torsional effects in the $S_{1}$ state. In addition, these distributions are shifted toward smaller distances, an effect that was also shown for PS (Figure 7). In Figures 10a1, 10b1, and 10c1, the excitation and fluorescence emission spectra are plotted for the meso24, meso10, and racemic samples, respectively. The respective excimer-like and excimer contributions are presented in Figures 10a2, 10b2, and $10 \mathrm{c} 2$, while the exciplex-like and exciplex contributions are shown in Figures 10a3, 10b3, and 10c3.

First, the monomer excitation/emission contributes the most to the spectra in Figures 10a1, 10b1, and 10c1. The monomer intensity drops considerably in simulations of single-chain PVK molecules since larger populations of excimers are obtained (see above discussion). Thus, intermolecular interactions prevent the formation of excimers in condensed media, and large populations of excimers are expected in dilute solutions of PVK. Second, the fluorescence emission spectrum shifts to longer wavelengths, a consequence of excimer formation. This effect is highlighted in Figures 10a2, 10b2, and 10c2. However, it is interesting to note that this shift is not observed for exciplex configurations. This is because the PES (both $\mathrm{S}_{0}$ and $\mathrm{S}_{1}$ states) varies smoothly in this region of the phase space (Figure 5 with $30^{\circ}<\varphi<90^{\circ}$ and $3 \AA<R<4 \AA$ ). Finally, it is interesting to note the significant overlap between excimer and exciplex contributions and the difficulty to estimate the population of excimers and exciplexes only from experimental fluorescence spectra.

Last, comparison between PVK and PS shows interesting features. The PVK model that most resembles PS is the racemic sample. The distribution of the mean distance between consecutive chromophores (Figures 7 and 9c) and the excimer contribution to the excitation/emission spectra (Figures $8 \mathrm{~b}$ and 10c2) are highly similar. In the ground state, excimer-like configurations are not favored, contrarily to what is observed in the $S_{1}$ state. This effect is characterized by the sharp distribution of the mean distance between chromophores and the shift toward small $R$ (Figures 7 and 9c). In PS and racemic PVK, the low proportion of excimer-like dyads is due to the lack of helicoidal structure. This is because (1) the steric hindrance in PS is small and (2) $\varphi_{1}$ and $\varphi_{2}$ are evenly distributed on the molecular chain in racemic $\mathrm{PVK}$.

\section{Conclusion}

The structural changes that take place when an aromaticcontaining polymer is photoexcited have been thoroughly investigated. First, the intermolecular potential between carbazyl or phenyl substituents was calculated with high-level ab initio methods and was shown to be in excellent agreement with experimental work. The decoupling of excimer and exciplex configurations from the simulated spectra provided key information. First, the separation between consecutive dyads is smaller in the excited state. This distance shift is correlated with the wavelength shift observed in the simulated spectra. On the contrary, the wavelength distributions are similar in the $S_{0}$ and $\mathrm{S}_{1}$ states for exciplexes. Second, unlike syndiotactic PVK, the isotactic structure favors excimer-like dyads in the ground state. In addition, the excimer population in the excited state depends strongly on the fraction of excimer-like dyads in the ground state at room temperature.

For all the simulations investigated here, the most important contribution to the simulated spectra is monomer excitation/ emission. This effect is due to intermolecular steric repulsions and is less important in simulations of single-chain polymers. Thus, the structure of macromolecules in condensed or in dilute media is expected to differ significantly.

Acknowledgment. Dr. P.-O. Bussière is gratefully acknowledged for fruitful discussions about his experimental fluorescence work on PVK.

\section{References and Notes}

(1) Yanari, S. S.; Bovey, F. A.; Lumry, R. Nature 2000, 200, 242.

(2) Vala, M. T.; Haebig, J.; Rice, S. A. J. Chem. Phys. 1965, 43, 886.

(3) Itaya, A.; Okamoto, K.; Kusabayashi, S. Bull. Chem. Soc. Jpn. 1976, 49, 2082.

(4) De Schryver, F. C.; Vendendriessche, J.; Toppet, S.; Demeyer, K.; Boens, N. Macromolecules 1982, 15, 406.

(5) Phillips, D. In Polymer Photophysics: Luminescence, Energy Migration and Molecular Motion in Synthetic Polymers; Phillips, D., Ed.; Chapman and Hall: London, 1985.

(6) Tsai, F.-J.; Torkelson, J. M. Polymer 1988, 29, 1004.

(7) Wandelt, B. Polymer 1991, 32, 2707.

(8) Chakraborty, D. K.; Kurian, J.; Trumbo, D.; Harwood, H. J.; Kennedy, J. P.; Mattice, W. L. Makromol. Chem. 1993, 194, 329.

(9) Hofstraat, J. W.; Verhey, H. J.; Verhoeven, J. W.; Kumke, M. U.; Li, G.; Hemmingsen, S. L.; McGown, L. B. Polymer 1997, 38, 2899.

(10) Inoue, M.; Inokuchi, M.; Itoh, Y.; Shirai, H.; Suzuki, S. Eur. Polym. J. 2000, 36, 303.

(11) Klöpffer, W. Chem. Phys. Lett. 1969, 4, 193

(12) Johnson, P. C.; Offen, H. W. J. Chem. Phys. 1971, 55, 2945.

(13) Rivaton, A.; Mailhot, B.; Derderian, G.; Bussière, P.-O.; Gardette, J.-L. Macromolecules 2003, 36, 5815.

(14) Evers, F.; Kobs, K.; Memming, R.; Terrell, D. R. J. Am. Chem. Soc. 1983, 105, 5988 .

(15) Gallego, J.; Pérez-Foullerat, D.; Mendicuti, F.; Mattice, W. L. J. Polym. Sci., Part B: Polym. Phys. 2001, 39, 1272.

(16) Sanz, A.; Mendicuti, F. Polymer 2002, 43, 6123.

(17) Karali, A.; Dais, P.; Mikros, E.; Heatley, F. Macromolecules 2001, $34,5547$.

(18) (a) Martin, O.; Mendicuti, F.; Saiz, E.; Mattice, W. L. J. Polym. Sci., Part B: Polym. Phys. 1996, 34, 2623. (b) Bahar, I.; Mattice, W. L. J. Chem. Phys. 1989, 90, 6775.

(19) Boyd, R. H. Macromolecules 1989, 22, 2477.

(20) (a) Mondello, M.; Yang, H.-J.; Furuya, H.; Roe, R.-J. Macromolecules 1994, 27, 3566. (b) Furuya, H.; Mondello, M.; Yang, H.-J.; Roe, R.-J. Macromolecules 1994, 27, 5674. (c) Roe, R.-J.; Mondello, M.; Furuya, H.; Yang, H.-J. Macromolecules 1995, 28, 2807. 
(21) Ayyagari, C.; Bedrov, D.; Smith, G. D. Macromolecules 2000, 33 6194.

(22) (a) Lyulin, A. V.; Michels, M. A. J. Macromolecules 2002, 35, 1463. (b) Lyulin, A. V.; Balabaev, N. K.; Michels, M. A. J. Macromolecules 2002, 35, 9595 .

(23) (a) Flory, P. J.; Sundararajan, P. R.; DeBolt, L. C. J. Am. Chem. Soc. 1974, 96, 5015. (b) Suter, U. W.; Flory, P. J. Macromolecules 1975 8, 765. (c) Yoon, D. Y.; Sundararajan, P. R.; Flory, P. J. Macromolecules 1975, 8, 776 .

(24) Vala, M. T.; Hillier, I. H.; Rice, S. A.; Jortner, J. J. Chem. Phys. 1966, 44, 23.

(25) Shinohara, H.; Nishi, N. J. Chem. Phys. 1989, 91, 6743. $(26)$

(27) Bagus, P. S.; Batra, I. P.; Clementi, E. Chem. Phys. Lett. 1973, 23 305

(28) Belletête, M.; Bédard, M.; Leclerc, M.; Durocher, G. J. Mol. Struct. (THEOCHEM) 2004, 679, 9.

(29) (a) Chakraborty, T.; Lim, E. C. Chem. Phys. Lett. 1993, 207, 99.

(b) Yip, W. T.; Levy, D. H. J. Phys. Chem. 1996, 100, 11539.

(30) Janda, K. C.; Hemminger, J. C.; Winn, J. S.; Novick, S. E.; Harris,

S. J.; Klemperer, W. J. Chem. Phys. 1975, 63, 1419.

(31) Hopkins, J. B.; Powers, D. E.; Smalley, R. E. J. Phys. Chem. 1981, 85,3739 .

(32) Law, K. S.; Schauer, M.; Bernstein, E. R. J. Chem. Phys. 1984, 81,4871 .

(33) Krätzschmar, O.; Selzle, H. L.; Schlag, E. W. J. Phys. Chem. 1994, 98,3501 .

(34) Ebata, T.; Hamakado, M.; Moriyama, S.; Morioka, Y.; Ito, M. Chem. Phys. Lett. 1992, 199, 33.

(35) Saigusa, H.; Sun, S.; Lim, E. C. J. Phys. Chem. 1992, 96, 2083.

(36) Saigusa, H.; Morohoshi, M.; Tsuchiya, S. J. Phys. Chem. A 2001 105,7334 .

(37) Doris, K. A.; Ellis, D. E.; Ratner, M. A.; Marks, T. J. J. Am. Chem. Soc. 1984, 106, 2491.

(38) Schauer, M.; Bernstein, E. R. J. Chem. Phys. 1985, 82, 3722.

(39) Price, S. L.; Stone, A. J. J. Chem. Phys. 1987, 86, 2859.

(40) Cársky, P.; Selzle, H. L.; Schlag, E. W. Chem. Phys. 1988, 125, 165.

(41) Hobza, P.; Selzle, H. L.; Schlag, E. W. Chem. Rev. 1994, 94, 1767.

(42) Hobza, P.; Selzle, H. L.; Schlag, E. W. J. Phys. Chem. 1996, 100 18790

(43) (a) Miyoshi, E.; Ichikawa, T.; Sumi, T.; Sakai, Y.; Shida, N. Chem. Phys. Lett. 1997, 275, 404. (b) Miyoshi, E.; Yamamoto, N.; Sekiya, M.; Tanaka, K. Mol. Phys. 2003, 101, 227.

(44) Tsuzuki, S.; Uchimaru, T.; Matsumura, K.; Mikami, M.; Tanabe, K. Chem. Phys. Lett. 2000, 319, 547.

(45) Gonzalez, C.; Lim, E. C. J. Phys. Chem. A. 2000, 104, 2953

(46) Kroon-Batenburg, L. M. J.; van Duijneveldt, F. B. J. Mol. Struct.

$1985,121,185$

(47) Nakano, H. J. Chem. Phys. 1993, 99, 7983.
(48) (a) GAMESS, revision 4.0; Feb 16, 2002. (b) Schmidt, M. W.; Baldridge, K. K.; Boatz, J. A.; Elbert, S. T.; Gordon, M. S.; Jensen, J. J.; Koseki, S.; Matsunaga, N.; Nguyen, K. A.; Su, S.; Windus, T. L.; Dupuis, M.; Montgomery, J. A., J. Comput. Chem. 1993, 14, 1347.

(49) Frisch, M. J.; Trucks, G. W.; Schlegel, H. B.; Scuseria, G. E.; Robb, M. A.; Cheeseman, J. R.; Montgomery, J. A., Jr.; Vreven, T.; Kudin, K. N.; Burant, J. C.; Millam, J. M.; Iyengar, S. S.; Tomasi, J.; Barone, V.; Mennucci, B.; Cossi, M.; Scalmani, G.; Rega, N.; Petersson, G. A Nakatsuji, H.; Hada, M.; Ehara, M.; Toyota, K.; Fukuda, R.; Hasegawa, J.; Ishida, M.; Nakajima, T.; Honda, Y.; Kitao, O.; Nakai, H.; Klene, M.; Li, X.; Knox, J. E.; Hratchian, H. P.; Cross, J. B.; Bakken, V.; Adamo, C.; Jaramillo, J.; Gomperts, R.; Stratmann, R. E.; Yazyev, O.; Austin, A. J.; Cammi, R.; Pomelli, C.; Ochterski, J. W.; Ayala, P. Y.; Morokuma, K.; Voth, G. A.; Salvador, P.; Dannenberg, J. J.; Zakrzewski, V. G.; Dapprich, S.; Daniels, A. D.; Strain, M. C.; Farkas, O.; Malick, D. K.; Rabuck, A. D.; Raghavachari, K.; Foresman, J. B.; Ortiz, J. V.; Cui, Q.; Baboul, A. G.; Clifford, S.; Cioslowski, J.; Stefanov, B. B.; Liu, G.; Liashenko, A.; Piskorz, P.; Komaromi, I.; Martin, R. L.; Fox, D. J.; Keith, T.; Al-Laham, M. A.; Peng, C. Y.; Nanayakkara, A.; Challacombe, M.; Gill, P. M. W. Johnson, B.; Chen, W.; Wong, M. W.; Gonzalez, C.; Pople, J. A. Gaussian 03, revision B.04; Gaussian, Inc.: Wallingford, CT, 2004.

(50) The MP2 and $\operatorname{CCSD}(\mathrm{T})$ results in Figure 3a (sandwich-like configuration) are identical to those of ref 42 . However, our MP4 results include single, double, and quadrupole excitations, which were not covered by the MP4 calculations in ref 42 . The basis set used here is labeled Basis Set III in ref 42.

(51) (a) Birks, J. B. Rep. Prog. Phys. 1975, 38, 903. (b) Cundall, R. B.; Robinson, D. A. J. Chem. Soc., Faraday Trans. 2 1972, 68, 1133.

(52) Ivanova, T. V.; Mokeeva, G. A.; Sveshnikov, B. Y. Opt. Spectrosc. 1962, 12, 325

(53) Bloński, S.; Sienicki, K.; Herman, A. Macromolecules 1987, 20, 329

(54) This is consistent with the distribution of the mean distance between consecutive phenyl rings found in this work from molecular dynamics simulations of PS in the $\mathrm{S}_{1}$ state and at room temperature (see Molecular Dynamics section).

(55) Canuto, S.; Zerner, M. C. J. Am. Chem. Soc. 1990, 112, 2114

(56) Hope, H.; Bernstein, J.; Trueblood, K. N. Acta Crystallogr., Sect. $B$ 1972, 28, 1733 .

(57) Gantzel, P. K.; Trueblood, K. N. Acta Crystallogr. 1965, 18, 958. 480 .

(59) Verlet, L. Phys. Rev. 1967, 98, 159

(60) Berendsen, H. J. C.; Postma, J. P. M.; van Gunsteren, W. F.; DiNola, A.; Haak, J. R. J. Chem. Phys. 1984, 81, 3684.

(61) Theodorou, D. N.; Suter, U. W. Macromolecules 1985, 18, 1467.

(62) Materials Studio, version 3.0; Accelrys, Inc.: San Diego, CA, 2003.

(63) Andersen, H. C. J. Chem. Phys. 1990, 72, 2384.

(64) Sun, H. J. Comput. Chem. 1994, 15, 752.

(65) Smith, G. D.; Jaffe, R. L. J. Phys. Chem. 1996, 100, 9624 